\title{
Transmissibilidade do Fusarium moniliforme em sementes de milho sob diferentes períodos de exposição
}

\author{
Ana Alice Rocha Cardoso ${ }^{\mathrm{a}} \odot$, Warlyton Silva Martins ${ }^{\mathrm{b}^{*}}$, Flávia Fernandes Ribeiro de Miranda ${ }^{\mathrm{a}} \oplus$
}

${ }^{a}$ Centro Universitário Católica do Tocantins, Brasil

${ }^{\mathrm{b}}$ Universidade Estadual de Ponta Grossa, Brasil

*Autor correspondente (warlytonsilva@gmail.com)

\section{N F O}

\section{Keyworks} germination incidence sanity

\begin{abstract}
A B S T R A C T
Transmissibility of Fusarium moniliforme in maize seeds under different exposure periods

Fusarium moniliforme is the main pathogen associated with corn seeds in Brazil. It is considered one of the main responsible for the deterioration of seeds, death of seedlings, root rot, stem rot and ear and grain rot. The objective of the present study was to evaluate the transmissibility of the Fusarium moniliforme fungus in corn seeds under different periods of exposure $(0,24,48$ and $72 \mathrm{~h})$. The experimental design had five replications and four treatments for each factor evaluated, adopting a completely randomized design. The fungus was obtained from the mycological collection of the Laboratory of Phytopathology of the Centro Universitário Católica do Tocantins and they were inoculated by depositing them on the fungus mycelium. The seed health test and the paper roll germination test were used. The exposure time significantly influenced $(\mathrm{p}<0.05)$ the incidence of the fungus, so that, at 48 hours, the pathogen had already infested $100 \%$ of the seeds. The germination rate was negatively influenced by the presence of the fungus, however, seeds exposed to the pathogen for 24,48 and 72 hours showed statistically similar germination rates $(p>0.05)$. It is concluded that the minimum period of 24 hours of contact of maize seeds with Fusarium moniliforme was sufficient for the occurrence of infection, reducing the germinative performance of seed lots.
\end{abstract}

\section{R E S U M O}

O Fusarium moniliforme é o principal patógeno associado a sementes de milho no Brasil. É considerado um dos principais responsáveis pela deterioração de sementes, morte de plântulas, podridão de radículas, podridão de colmo e podridão da espiga e dos grãos. Objetivou-se no presente estudo avaliar a transmissibilidade do fungo Fusarium moniliforme em sementes de milho sob diferentes períodos de exposição $(0,24,48$ e $72 h)$ das sementes. O delineamento experimental contou com cinco repetições e quatro tratamentos para cada fator avaliado, adotado o delineamento inteiramente casualizado. $\mathrm{O}$ fungo foi obtido da coleção micológica do Laboratório de Fitopatologia do Centro Universitário Católica do Tocantins e foram inoculadas por meio da deposição das sementes sobre o micélio do fungo. Utilizou-se o teste de sanidade de sementes e o teste de germinação em rolo de papel. $O$ tempo de exposição influenciou significativamente $(\mathrm{p}<0,05)$ sobre a incidência do fungo, de modo que, às 48 horas o patógeno já havia infestado $100 \%$ das sementes. A taxa de germinação foi influenciada negativamente pela presença do fungo, entretanto, sementes expostas ao patógeno por 24,48 e 72 horas apresentaram taxas germinativas semelhantes estatisticamente $(\mathrm{p}>0,05)$. Conclui-se que o período mínimo de 24 horas de contato das sementes de milho com Fusarium moniliforme foi suficiente para a ocorrência de infecção reduzindo o desempenho germinativo dos lotes de sementes. 


\section{INTRODUÇÃO}

$\mathrm{O}$ milho é um dos cereais com maiores áreas cultivadas no mundo, em detrimento de suas variadas formas de utilização, desde a produção de alimentos básicos, produção de ração animal e produção de etanol (Carvalho et al., 2020).

Seu cultivo é realizado em quase todos os continentes, principalmente nas Américas, uma vez que os Estados Unidos e o Brasil são grandes produtores (Usda, 2020). No total, o Brasil na safra 2019/20 apresentou uma área de 18,2 milhões hectares e uma produção estimada de 101,9 milhões de toneladas. Para o Tocantins, a safra deve ter incremento tanto na área quanto na produção, se comparado a safra anterior (CONAB, 2020).

Associada ao crescimento do cultivo da cultura, fatores de caráter sanitário têm limitado a produção em diferentes regiões produtoras do grão. Nos últimos anos tem crescido bastante a incidência e a gravidade de doenças na cultura do milho, em virtude, principalmente, das alterações que vem ocorrendo no clima, das mudanças no sistema de produção, período de plantio, de plantios subsequentes, pela expansão das áreas de cultivo para outras regiões, e ainda, pela falta de rotação de culturas (Chavaglia et al., 2020).

A maioria das doenças que atingem a cultura do milho possui seus agentes causais transmitidos pelas sementes, desta forma, são consideradas eficientes meios de disseminação de patógenos (Prestes et al., 2019). Nesse contexto, os fungos são os principais microrganismos disseminados por sementes, podendo ser carregados por longas distâncias e introduzidos em locais livres da incidência de doenças. Além disso, as sementes contaminadas podem ocasionar sérios problemas de germinação, emergência das plântulas e podridões radiculares e da base do colmo (Costa et al., 2020).

No Brasil, entre os fungos de campo disseminados por sementes, o Fusarium moniliforme é o que apresenta com maior frequência (Prestes et al., 2019). Em milho, um dos principais sintomas são os colmos ficando podres. Os sintomas na parte interna são caracterizados por mudanças na cor da medula, que pode ficar esbranquiçado ou de coloração marrom. Os efeitos em estágios avançados podem chegar até a quebra do colmo. Além disso, o fungo é responsável por introduzir as micotoxinas, zearalenona, fumonisinas e vomitoxinas em espigas, grãos armazenados e morte de plântulas (Bento et al., 2012).

Nesse contexto, garantir a sanidade das sementes de milho é um dos fundamentais fatores que condicionam o seu desempenho no campo, o estabelecimento de um bom estande e, consequentemente, uma boa produção sem riscos à saúde humana e animal (Medeiros et al., 2020). Objetivou-se, com este trabalho, determinar o período mínimo necessário para a contaminação de sementes de milho por Fusarium moniliforme.

\section{MATERIAL E MÉTODOS}

\section{Local de Pesquisa}

O experimento foi conduzido em laboratório de fitopatologia e casa de vegetação do Centro Universitário Católica do Tocantins - UniCatólica, Campus de Ciências Agrárias e Ambientais em Palmas - TO, no período compreendido entre fevereiro e maio de 2019.

\section{Obtenção e inoculação do isolado}

O fungo Fusarium moniliforme foi obtido da coleção micológica do Laboratório de Fitopatologia do Centro Universitário Católica do Tocantins, e replicado em meio de cultura de batata-dextrose-ágar (BDA) incubado em câmara BOD (Demanda Bioquímica de Oxigênio) com temperatura média $3 \pm 25^{\circ} \mathrm{C}$, com fotoperíodo de 12 horas, por 15 dias.

\section{Delineamento experimental}

Adotou-se o Delineamento Inteiramente Casualizado, consistindo em quatro tratamentos (diferentes períodos de exposição das sementes ao fungo): T1 -0 horas; $\mathrm{T} 2-24$ horas; $\mathrm{T} 3-48$ horas; T4 - 72 horas, com cinco repetições.

\section{Inoculação das sementes}

Sementes do Híbrido de milho 2B688 PW foram inoculadas com Fusarium moniliforme por meio da deposição destas sobre o micélio do fungo, de forma que todas as sementes permanecessem em contato com a estrutura de acordo com o tempo de exposição de cada tratamento. Em seguida, foram submetidas ao teste de sanidade, com desinfestação superficial.

A desinfestação foi executada após a incubação, por meio da imersão de uma amostra com 500 sementes por tratamento em solução de hipoclorito de sódio a $1 \%$, durante 3 minutos. Após esta etapa, as sementes foram lavadas com água esterilizada e secas à temperatura ambiente.

\section{Teste de sanidade}

O teste de sanidade foi realizado através do método de papel filtro sem congelamento descrito pelas Regras de Análise de Sementes (RAS) (Brasil, 2009). Foram utilizadas 100 sementes para cada repetição, e distribuídas em gerboxes previamente esterilizados com álcool $70 \%$, sobre duas folhas de papel filtro umedecidas com água 
destilada, e incubadas em temperatura ambiente de aproximadamente $3 \pm 25^{\circ} \mathrm{C}$., durante 7 dias.

Após a incubação as sementes foram avaliadas com auxílio de microscópio óptico identificando e quantificando a presença do fungo Fusarium moniliforme.

Os dados foram expressos em porcentagem de incidência (Brasil, 2009).

Teste de germinação

O teste foi realizado com 100 sementes por repetição, em papel germitest, em que o umedecimento do papel foi executado com quantidade de água equivalente a 2,5 o peso do substrato seco, mantidos em temperatura ambiente de aproximadamente $3 \pm 25^{\circ} \mathrm{C}$.

Os testes foram interpretados aos 4 e aos 7 dias após a semeadura, e os resultados expressos em porcentagem de plântulas normais (Brasil, 2009).

\section{Análises estatísticas}

Os dados obtidos foram submetidos à análise de variância pelo teste $\mathrm{F}$, e as médias comparadas pelo teste Scott \& Knott ao nível de 5\% de probabilidade, através do software AGROESTAT 1.0 (Barbosa e Maldonado Júnior, 2015).

\section{RESULTADOS E DISCUSSÃO}

O resumo da análise de variância para os fatores avaliados, conforme a tabela 1 , mostra significância ao nível de $1 \%$ de probabilidade $(\mathrm{p}<0,01)$ para a taxa de incidência (INC) e germinação (GER) de acordo com os tempos de exposição ao fungo avaliado.

Tabela 1 - Resumo da análise de variância da taxa de incidência (INC) e germinação (GER) de sementes de milho inoculadas por Fusarium moniliforme e submetidas a diferentes tempos de exposição ao fungo.

\begin{tabular}{ccc}
\hline \multirow{2}{*}{ FATOR DE VARIAÇÃO } & \multicolumn{2}{c}{ QUADRO DE ANÁLISE } \\
\cline { 2 - 3 } & INC & GER \\
\hline Tempos de Exposição $\left(41^{\circ} \mathrm{C}\right)$ & $302,58 * *$ & $* 2 *$ \\
C.V $(\%)$ & 9,43 & 11,45 \\
\hline ** significativo ao nível de $1 \%$ de probabilidade $(\mathrm{p}<0,01),{ }^{*}$ significativo ao nível de $5 \%$ de probabilidade $(0,01=<\mathrm{p}<0,05)$ e ns não \\
significativo $(\mathrm{p}>=0,05)$, respectivamente, pelo teste $\mathrm{F}$.
\end{tabular}

Na tabela 2 estão dispostos os resultados médios para a taxa de incidência fúngica e germinação. Observa-se que houve diferença estatística entre os fatores, salientando que as médias referentes a incidência do fungo Fusarium moniliforme nas sementes cresceram significativamente à medida em que ocorreu o aumento do tempo de exposição ao fungo.

Tabela 2 - Comparação estatística das médias para incidência (INC) e germinação (GER) de sementes de milho sob diferentes tempos de exposição ao fungo Fusarium moniliforme.

\begin{tabular}{ccc}
\hline \multirow{2}{*}{ Tempo de exposição } & Incidência & Germinação \\
\cline { 2 - 3 } & $(\%)$ & $(\%)$ \\
\hline 0 horas & $0,00 \mathrm{c}$ & $93,50^{\mathrm{a}}$ \\
24 horas & $58,00 \mathrm{~b}$ & $59,50 \mathrm{~b}$ \\
48 horas & $100,00 \mathrm{a}$ & $73,00 \mathrm{~b}$ \\
72 horas & $100,00 \mathrm{a}$ & $68,00 \mathrm{~b}$ \\
\hline
\end{tabular}

As médias seguidas pela mesma letra não diferem estatisticamente entre si. Foi aplicado o Teste de Scott \& Knott ao nível de 5\% de probabilidade.

Observou-se, conforme a tabela 2, que mostras submetidas a 24 horas de exposição ao fungo, proporcionou $58 \%$ de incidência em média, se comparadas à testemunha. Em contrapartida, a infestação total das amostras foi atingida nas sementes expostas por 48 e 72 horas, observando uma incidência total de $100 \%$ se comparadas à testemunha. Os resultados corroboram com os achados de Ramos et al. (2014) que, estudando a infecção por Fusarium graminearum e Fusarium verticillioides em sementes de milho, concluíram que o período de 16 horas de contato das sementes de milho com $F$. graminearum e $F$. verticillioides foi suficiente para a ocorrência de infecção. $F$. graminearum e $F$. verticillioides não interferiram na germinação de sementes de milho, contudo, $F$. graminearum reduziu o desempenho dos lotes de sementes. Para a germinação, todos os tempos de exposição ao fungo mostraram efeito sobre o potencial germinativo dessas sementes. Se comparadas à testemunha, os tempos de 24, 48 e 72 horas, reduziram em 59,5, 73 e $68 \%$, respectivamente, a germinação (Figura 1). 


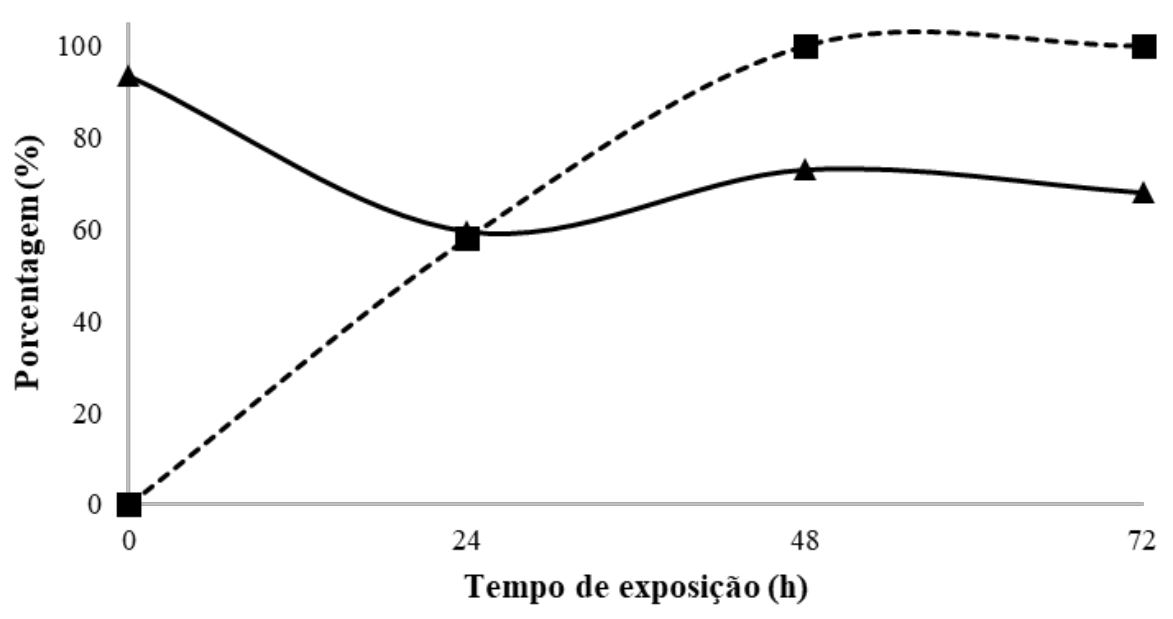

--E--Incidência (\%) —— Germinação (\%)

Figura 1 - Desempenho fisiológico para incidência (INC) e germinação (GER) em sementes de milhos submetidas a diferentes tempos de exposição ao fungo Fusarium moniliforme.

Os resultados obtidos na presente pesquisa estão de acordo aos de Costa et al. (2003), que avaliando o efeito do tempo de exposição sobre a incidência do fungo Fusarium oxysporum em sementes de feijão, também observaram que a incidência crescia na medida em que as sementes continuavam expostas. Os autores relataram que no menor tempo de exposição (32 horas) o fungo incidiu sobre 24, $39 \%$ das sementes, já no maior tempo de exposição (144 horas) a incidência atingiu 70,06\%.

Observando a percentual de incidência 24 e 48 horas após a inoculação do fungo Rhizoctonia solani em sementes de algodoeiro, Braghin et al. (2014), constataram o mesmo efeito, ou seja, as sementes expostas por um maior tempo (48 horas) apresentaram um percentual de infestação superior ( $99 \%$ de incidência nas sementes) às expostas por um menor tempo (24 horas).

De igual modo, Ramos et al. (2014), observaram que a exposição dos fungos Fusarium graminearum e Fusarium verticillioides a sementes de milho causou infestação já nas primeiras horas, e essa taxa cresceu conforme ocorreu aumento no tempo de exposição. Porém, os autores relatam que foram necessárias 32 horas para que ocorresse a infecção das sementes pelos dois fungos.

Contrariando os resultados obtidos pelos autores descritos acima, Teixeira et al. (2005), avaliando a incidência do fungo Acremonium strictum em sementes de milho expostas por 24, 36, 72 e 96 horas, observaram que a incidência do fungo não foi influenciada pelo tempo de exposição. Em relação as informações apresentadas, os diferentes resultados podem ser justificados pelo fato de a propagação de fungos depender também de fatores como idade, tipo e condições dos tecidos do hospedeiro (Ramos et al., 2014).

Trabalhos realizados por Moraes et al. (2003), Cappelini et al. (2008), Henning et al. (2011) e Solorzano e Malvick (2011) demonstraram que esses fungos não afetam a germinação de sementes de milho. Todavia, a redução na germinação de sementes de milho infectadas por $F$. miniliforme é possível, pois este fungo apresenta crescimento rápido e agressivo, e pode causar a morte das sementes antes mesmo da germinação (Antonello et al. 2009).

\section{CONCLUSÃO}

O período mínimo de 24 horas de contato das sementes de milho com Fusarium moniliforme foi suficiente para a ocorrência de infecção reduzindo o desempenho germinativo dos lotes de sementes.

\section{REFERÊNCIAS BIBLIOGRÁFICAS}

Antonello LM, Muniz MB, Brand SC, Vidal MD, Garcia D, Ribeiro L, Santos VD. Qualidade de sementes de milho armazenadas em diferentes embalagens. Ciência Rural, Santa Maria, v. 39, n. 7, p. 2191-2194, 2009. https://doi.org/10.1590/S0103-84782009005000157.

Barbosa JC, Maldonado Junior W. AgroEstat: sistema para análises estatísticas de ensaios agronômicos. Jaboticabal, FCAV/UNESP. 396p, 2015.

Bento LF, Caneppele MAB, Albuquerque MCDF, Kobayasti L, Caneppele C, Andrade PDJ. Ocorrência de fungos e aflatoxinas em grãos de milho. Revista do Instituto Adolfo Lutz (Impresso), v.71, n.1, p.44-49, 2012.

Braghin PA, de Araujo DV, Batistti M, Krause W, Dias LDE, Rosa HHR. Eficiência do controle químico em sementes de 
algodoeiro inoculadas com Rhizoctonia solani. Enciclopédia Biosfera, Centro Científico Conhecer, Goiânia, v.10, n.18, p.1464-1475, jul. 2014.

Brasil. Ministério da Agricultura Pecuária e Abastecimento. Regras para análise de sementes. Secretaria de Defesa Agropecuária. Brasília: SNDA/DNDV/CLAV, 395 p. 2009. Disponível em: http://www.agricultura.gov.br/assuntos/insumos-agropecuarios/arquivos-publicacoes-insumos/2946_regras_analise_sementes.pdf. Acesso em: 08 set. 2020.

Carvalho MS, Martins Ana P, Milho J. Railway seat design for injury mitigation in crash scenario. International Journal of Rail Transportation, v.8, n.3, p.215-233, 2020. https://doi.org/10.1080/23248378.2019.1636318.

Cappelini LTD, de Cássia Panizzi R., Vieira RD, Galli J. A. (2008). Efeito de Fusarium moniliforme na qualidade de sementes de milho. Científica, v. 33, n. 2, p. 185-191, 2008 .

Chavaglia AC, Civardi EA, Pinto JFN, dos Reis EF. Dissimilaridade genética para resistência a doenças foliares associado ao potencial agronômico em milho. Revista Caatinga, v.33, n.4, p.936-944, 2020. http://dx.doi.org/10.1590/198321252020v33n408rc.

CONAB - Companhia Nacional de Abastecimento. 2020. Boletim da safra de grãos. $11^{\circ}$ Levantamento - Safra 2019/20 - Safra 2019/20. Disponível em: https://www.conab.gov.br/info-agro/safras/graos/boletim-da-safra-degraos. Acesso em 11 dez. 2020.

Costa MLN, Machado JDC, Guimarães RM, Pozza EA, Oride D. Inoculação de Fusarium oxysporum f. sp. phaseoli em sementes de feijoeiro através de restrição hídrica. Ciência e Agrotecnologia, v.27, n.5, p.1023-1030, set./out. 2003. https://doi.org/10.1590/S141370542003000500008 .

Costa MLN; Gonçalves DSF, Machado JC. Controle de Fusarium verticillioides em sementes de milho com o óleo essencial de gengibre. Summa Phytopathologica, v.46, n.3, p.250-254, 2020. https://doi.org/10.1590/0100$5405 / 233888$.

Henning FA, Jacob Junior EA, Mertz LM, Peske ST. et al. Qualidade sanitária de sementes de milho em diferentes estádios de maturação. Revista Brasileira de Sementes, Londrina, v.33, n.2, p.316-321, 2011 https://doi.org/10.1590/S0101-31222011000200014.

Medeiros JCD, Martins WS, Miranda FFR. Antagonismo de Trichoderma spp. no biocontrole de Fusarium moniliforme na cultura do milho. Revista Sítio Novo, v. 4, n. 4, p. 169$178,2020$.

Moraes MH, Menten JO, Gravena JC, Alves CA. Controle químico de Fusarium moniliforme em sementes de milho: metodologia de avaliação e efeitos sobre a qualidade fisiológica. Fitopatologia Brasileira, Brasília, DF, v.28, n.6, p.626- 632, 2003. https://doi.org/10.1590/S010041582003000600008 .

Prestes ID, Rocha LO, Nuñez KV, Silva NC. Principais fungos e micotoxinas em grãos de milho e suas consequências. Scientia Agropecuaria, v.10, n.4, p.559-570, 2019. http://dx.doi.org/10.17268/sci.agropecu.2019.04.13.
Ramos DP, Barbosa RM, Vieira BGTL, Panizzi RDC, Vieira RD. Infecção por Fusarium graminearum e Fusarium verticillioides em sementes de milho. Pesquisa Agropecuária Tropical (Agricultural Research in the Tropics), Goiânia, v.44, n.3, p.24-31, jan./mar. 2014. https://doi.org/10.1590/S1983-40632014000100011.

Panizzi RC, Vieira RD, Altafin G. Effect of Fusarium moniliforme on the quality of maize seeds. Científica, Jaboticabal, v.33, n.2, p.185-191, 2005.

Solorzano CD; Malvick DK. Effects of fungicide seed treatments on germination, population, and yield of maize grown from seed infected with fungal pathogens. Field Crops Research, Amsterdam, v.122, n.1, p.173-178, 2011. https://doi.org/10.1016/j.fcr.2011.02.011.

Teixeira H, Machado JDC, Oride D, Alves MC, Noda A. Técnica de restrição hídrica: efeito sobre Acremonium strictum, protrusão de sementes e obtenção de sementes de milho infetadas. Fitopatologia Brasileira, v.30, n.2, p.109114, mar./abr. 2005. https://doi.org/10.1590/S010041582005000200001 .

Usda - United States Departamente of Agriculture. 2020. World Agricultural Production. Disponível em: https://downloads.usda.library.cornell.edu/usdaesmis/files/5q47rn72z/dz0117445/qv33sf19j/production.pdf> Acesso em: 29 dez. 2020. 